\title{
Correction to: Fibroblast-to-myofibroblast transition in bronchial asthma
}

\author{
Marta Michalik ${ }^{1}$ (1) $\cdot$ Katarzyna Wójcik-Pszczoła ${ }^{1,2} \cdot$ Milena Paw $^{1} \cdot$ Dawid Wnuk $^{1} \cdot$ Paulina Koczurkiewicz $^{1,2}$. \\ Marek Sanak $^{3} \cdot$ Elżbieta Pękala $^{2} \cdot$ Zbigniew Madeja $^{1}$
}

Published online: 29 August 2018

C) Springer Nature Switzerland AG 2018

\section{Correction to: Cellular and Molecular Life Sciences https://doi.org/10.1007/s00018-018-2899-4}

In the original publication, funding information was inadvertently omitted. The complete funding information was included in the below 'Acknowledgements' section.

Acknowledgements The work Fibroblast-to-myofibroblast transition in bronchial asthma' (https://doi.org/10.1007/s00018-018-2899-4) was supported by a grant from the National Science Centre 2015/17/B/ NZ3/02248, Poland. Faculty of Biochemistry, Biophysics and Biotechnology of the Jagiellonian University is a partner of the Leading National Research Centre (KNOW) supported by the Ministry of Science and Higher Education.

Marta Michalik

marta.michalik@uj.edu.pl

$\triangle$ Katarzyna Wójcik-Pszczoła

katarzynaanna.wojcik@uj.edu.pl

1 Department of Cell Biology, Faculty of Biochemistry, Biophysics and Biotechnology, Jagiellonian University,

Gronostajowa 7, 30-387 Kraków, Poland

2 Department of Pharmaceutical Biochemistry, Faculty of Pharmacy, Jagiellonian University Medical College, Medyczna 9, 30-688 Kraków, Poland

3 Division of Molecular Biology and Clinical Genetics, Department of Medicine, Jagiellonian University Medical College, Skawińska 8, 31-066 Kraków, Poland 